\title{
TOWARDS ESTABLISHING TRUST RELATIONSHIPS AMONG ORGANIZATIONS IN VBES
}

\author{
Simon Samwel Msanjila, Hamideh Afsarmanesh \\ University of Amsterdam, NETHERLANDS \\ msanjila@science.uva.nl,hamideh@science.uva.nl
}

\begin{abstract}
Organizations compete in acquiring competitive resources, knowledge, and competencies. However, in the current market, when an opportunity is brokered, organizations need to collaborate, more than competing, by sharing the acquired resources, knowledge, and competencies to respond to the opportunity which none of them could handle otherwise. This means organizational strategies must now adapt to the notion of collaboration with others. One important organizational strategy necessary in the virtual organization breeding environment (VBE) is focused on the organizational preparedness that is required to enhance the chances of participating in virtual organizations (VOs). A crucial aspect of preparedness is the establishment of trust relationships with other member organizations to smoothen the sharing of resources, knowledge, and competence, and in turn facilitate the organizations' collaboration. In this paper we address approaches and mechanisms for establishment of trust relationships among member organizations in VBEs.
\end{abstract}

\section{INTRODUCTION}

The word "trust" as used daily by individuals refers to the opinion of somebody about another person. It is not only an estimation of another's intention, but also the possible competencies of others that are needed to establish trust relationships among people. Gambetta [Gambetta, D. 1988] provided a definition of trust, which has been widely used, as the subjective probability by which an individual " $A$ " expects another individual " $B$ " to perform a given action on which $A$ 's welfare depends. Trust is a subject, which is studied by researchers in various disciplines from which different definitions are generated [Msanjila, S.S. et al 2007-1].

In VBE environments, trust relationships must be addressed from three points of view, including: the VBE member organizations, the external stakeholders, and the VBE administration. VBE members are organizations and not individuals, and VBE focuses on preparing its members for involvement in VOs [Afsarmanesh, $\mathrm{H}$. et al 2005]. Therefore, while this work can benefit from the general past research on trust relationships among individuals, their results cannot be directly applied.

Trust among organizations in VBEs is a complex subject, which must be addressed considering the interdisciplinarity, heterogeneity and contradictions among interests and goals of involved organizations [Msanjila, S.S. et al 2007-2]. In our study, identification and tuning of trust elements, modeling of trust relationships, assessment of trust level, and establishment and promotion of trust relationship constitute the main focus of the management of trust among organizations in VBEs. These specific topics are addressed considering the following three main trust objectives in VBEs, namely for creating trust and establishing trust relationships: (1) among VBE member organizations, (2) of the VBE member

Msanjila, S.S., Afsrarmancsh, H., 2007, in IFIP Intcrnational Federation for Information Processing, Volume 243, Establishing the Foundation of Collaborative Networks; eds. Camarinha-Matos, L., Afsarmanesh, H., Novais, P., Analide, C.; (Boston: Springer), pp. 3-14. 
organization to the VBE administration, and (3) of the external organization to the VBE. In [Msanjila, S.S. et al 2007-3] we addressed the identification of trust elements for organizations; in [Msanjila, S.S. et al 2007-1] we addressed the modeling of trust relationships among organizations, in [Msanjila, S.S. et al 2007-2] we addressed the assessment of trust level of organizations. This paper focuses on the establishment of trust relationships among organizations in VBEs by applying the trust models/elements as characterized in our previous work.

The remaining part of this paper is organized as follows: section 2 provides the definitions of base concepts. Section 3 describes the problem area and presents research questions. Section 4 addresses the antecedents and importance of trust. Section 5 addresses the establishment of trust relationships among organizations. Section 6 discusses the tradeoffs between risks and trust in VBEs. Section 7 addresses the importance of validity of information. Section 8 concludes the paper.

\section{DEFINITIONS OF MAIN CONCEPTS}

This section presents the definitions of the base concepts applied in this paper. These definitions are listed in Table 1 [Msanjila, S.S. et al 2007-1].

Table 1: definitions of important concepts

\begin{tabular}{|c|c|}
\hline Concept & Definition \\
\hline Trust actors & $\begin{array}{l}\text { Refer to the two organization parties involved in a specific trust relationship. The first party is the } \\
\text { organization that needs to assess the trustworthiness of another and is referred to as the trustor. The } \\
\text { second party is the organization that needs to be trusted, and thus its trust level will be assessed and is } \\
\text { referred to as the trustee. }\end{array}$ \\
\hline $\begin{array}{l}\text { Trust } \\
\text { objective }\end{array}$ & $\begin{array}{l}\text { Refers to the purpose for which the trust relationship establishment among the involved organizations is } \\
\text { required. Examples of trust objectives include the following: for inviting an organization to join a VO, } \\
\text { for appointing or selecting an organization as the VO coordinator, etc. }\end{array}$ \\
\hline $\begin{array}{l}\text { Trust } \\
\text { perspec }\end{array}$ & $\begin{array}{l}\text { Represents the specific "point of view" of the trustor on the main aspects that must be considered for } \\
\text { assessing the trust level of the trustee. }\end{array}$ \\
\hline $\begin{array}{l}\text { Trust } \\
\text { requirement }\end{array}$ & $\begin{array}{l}\text { Represents the essentials (cardinals) that characterize and guide on how the respective trust perspective } \\
\text { can be realized. Thus, trust requirements are the fundamental cardinals that guide or suggest what must } \\
\text { be met in order for the respective trust perspective to be realized. For instance, "financial stability" is an } \\
\text { example requirement that must be met to support the economical perspective, similarly "compliance } \\
\text { with community standards" is a requirement for the social perspective, etc. }\end{array}$ \\
\hline $\begin{array}{l}\text { Trust } \\
\text { criteria }\end{array}$ & $\begin{array}{l}\text { Represents the measurable trust elements that characterize a respective trust requirement. Therefore, for } \\
\text { each organization, the values of its trust criteria (related to a requirement) can be used to make an } \\
\text { objective fact-based judgment on whether the respective requirement is met. Each trust criteria } \\
\text { constitutes a value structure and the metric, which defines the acceptable structure and meaning for its } \\
\text { data, such as scalars, vectors, arrays, list of strings, etc. }\end{array}$ \\
\hline Trust level & $\begin{array}{l}\text { Refers to the intensity level of trust for a trustee in a trust relationship, based on the assessment of values } \\
\text { for a set of necessary trust criteria. Clearly enough, the criteria for the trust level assessment of } \\
\text { organizations are varied and wide in spectrum depending on the purpose (e.g. depending on the } \\
\text { requirements, the perspective, and the objective of trust establishment). When trust level is assessed for } \\
\text { a certain specific purpose, such as for inviting a member to a VO, and the assessment is based on } \\
\text { specific trust criteria for that the purpose, we call the results, specific trustworthiness of the trustee. }\end{array}$ \\
\hline $\begin{array}{l}\text { Trust } \\
\text { relationship }\end{array}$ & $\begin{array}{l}\text { A relationship is a state of connectedness among people or organizations or is a state involving mutual } \\
\text { dealing among parties. Trust relationship refers to the state of connectedness between a trustor and a } \\
\text { trustee whose intensity is characterized and based on the fact-based assessment of trust level. }\end{array}$ \\
\hline
\end{tabular}

\section{PROBLEM AREA AND RESEARCH QUESTIONS}

Trust is defined differently in different disciplines and research. Among others, the three following definitions are dominant:

1.Trust is the willingness of a trustor to be vulnerable to the actions of another party based on the expectations that the trustee will perform a particular action important to the trustor irrespective of the ability to monitor or control the trustee [Mayer, R. C. et al 1995].

2.Trust is the belief in the competency of an entity to act dependably, securely and reliably within a specified context [Grandison, T., et al 2000]. 
3.Trust is a psychological condition comprising the trustor's intention to accept vulnerability based upon expectation of trustee's intentions and behavior [Rousseau, D. M. et al 1998].

Traditionally, trust is subjective and thus the evaluation has been opinion-based. However, trust among organizations is the base for any collaborative transaction in which they get involved. Thus specifically for SMEs, their survivability may depend on getting involved in such collaborations. Therefore, opinion-based trust (subjective) is too risky and fact-based trust (objective) is required to be created among organizations to facilitate goal oriented collaborations.

The diversity among these definitions makes it difficult to properly characterize trust and its concepts. There are many theories on trust, some of which diverge from each other only in their identification of the grounds on which they are based [Rousseau, D.M. et al 1998]. Despite the difficulties in solidifying the definition of trust, in practice, trust is a base for collaboration among individuals as well as among organizations. Research addressing the subject of collaboration among organizations had reported that the effectiveness of VBE operation depends on the right balance of trust level among organizations [Msanjila, S.S. et al 2007-1].

Trust among organizations, as it is applied in VBEs, is defined as the objective-specific confidence of a trustor to a trustee based on the results of fact-based assessment of trust level of the trustee [Msanjila, S.S. et al 2007-3].

Therefore, objective based trust creation refers to the process of creating trust among organizations based on the results of the fact-based assessment of their trust levels. Only measurable or numeric data are applied for the assessment and the resulted trust levels can be supported with some formal reasoning applied during the assessment of trust level, which in turn enhances the reasoning of the established trust relationships [Msanjila, S.S. et al 2007-2]. While the importance of trust relationships is palpable for collaboration among organizations, the following three research questions must be addressed:

1. Can trustworthiness (trust level) of an organization be measured? How complex is trustworthiness? Does it have a quantitative value, and if so, what is the metric? Furthermore, is it one number or a set of numbers? If not quantitative, then is it a qualitative value, such as good/bad, high/low?

In [Msanjila, S.S et al 2007-2], we presented an approach for measuring trust level of organizations in terms of values of a set of trust-related criteria. We argued that trustworthiness is complex and can neither be measured with a single value nor interpreted with a single metric. The levels upon which the data about certain trust criteria in an organization meet the specified ratings represent its trust level.

2. Does every organization have the same objectives and perspectives for establishing trust relationship with others?

In VBEs, trust must be thoroughly characterized to ease the understanding about the motivations from which organizations prefer to establish trust relationships with others. Antecedents and importance of trust relationships among member organizations must be studied. This paper addresses this question.

3. How can establishment of trust among organizations in VBE be achieved and enhanced?

This paper addresses this question by providing approaches for establishing and promoting trust relationships among organizations in VBEs.

\section{ANTECEDENTS AND IMPORTANCE OF TRUST IN VBES}

In this section we address the antecedents and importance of trust relationships among organizations in VBEs. We first address the antecedents. 


\subsection{Antecedents for establishing trust relationships among organizations}

Trust antecedents are cardinal elements that may have positive or negative effects (impacts) on the effectiveness of the established trust relationships among organizations. In this work three antecedents are identified for organizations that are also partially studied in other research [Rtanasingam, P. 2004], namely: the shared values, the previous interactions, and the practiced behaviors.

Shared values occur when the trustor and the trustee have common understanding on important issues that might influence the creation of trust to each other, such as missions, goals, policies, interpretation of right or wrong etc. [Morgan, R.M. et al 1994]. Shared values can range from business objectives to the internal management processes and approaches. In business environments, it is more difficult to have shared values when the two organizations are competing than when they are complementing each other [Clay, K. et al 2000]. Typically, when two organizations have some common understanding, they both feel that there will not be unexpected results during the cooperation/collaboration, and thus it is easier to establish trust relationship between them. As an aspect of preparedness, the VBE must ensure member organizations do have some shared values.

Previous fruitful interactions between the trustor and the trustee either directly or indirectly (through other intermediate organizations) enhances the effectiveness of the established trust relationships. The interactions can be formal as well as informal, i.e. sharing meaningful and up-to-date information. Interactions can also involve individuals working in the two organizations. Although, there may be no existing business interactions, but the existence of previous interactions will enable fluid and smooth the establishment of trust relationship.

Practiced (moral and/or ethical) behaviours basically refer to acting against the opportunistic behaviour. Opportunistic behaviour refers to taking immediate advantage, often unethically, of any circumstance that may generate possible benefit. Opportunistic behaviour in competitive market seems natural because the focus of organizations in such environments is to acquire customers without caring the longterm relationships with other organizations. However, in collaborative networks, organizations must collaborate with others to serve the same customer. Opportunistic behaviour has a negative impact on the effectiveness of trust relationships. It has its roots in transaction cost literature and is defined as self-interest seeking with guile [Mukherjee, A. 2003]. In this paper we refer to opportunistic behaviour as ungentle action taken by VBE members for the purpose of benefiting themselves unethically more than others (e.g. quitting the collaboration once they gain, or if they expect for the risks of the collaboration to arise).

\subsection{Importance of establishing trust relationships among organizations}

The stability of a VBE requires delicate balance of trust level among the involved organizations in various specific trust relationships [Msanjila, S.S. et al 2007-1]. As explained earlier, VBEs are characterized as multi-actor environments, where each actor has autonomy, interests, and goals that might be contradicting to those of others. Interdisciplinary and heterogeneity nature among several aspects, such as business domains and technological aspects, are some issues that increase the complexity for creating trust among organizations in VBEs. A catalyser for enhancement of cooperation among member organizations in VBEs is the establishment of their trust relationships. That is why the past research pointed out 
that trust is the most salient factor for cooperation networks to achieve their objectives [Morgan, R.M. et al 1994]. Trust relationships among organizations are more important for industry-based VBEs that function under the pressure from global economy, the growing value of information, and the increasing uncertainties surrounding their businesses [Msanjila, S.S. et al 2007-1].

Several advantages can be gained once trust relationships among member organizations are properly established and managed. Among others the key advantages include: (1) Motivating member organizations to accept responsibilities in case of uncertain or incomplete information, (2) Facilitating the achievement of common goals by encouraging information exchange, knowledge sharing, tools sharing, etc., among member organizations, (3) Encouraging member organizations to avoid opportunistic behaviours during collaboration, (4) Easing the process of creating and launching VOs, (5) Creating competitive advantage by facilitating the reduction of governance, internalization (acquisitions), and transaction costs among organizations, (6) Enabling open communication, and reduces conflicts, (8) Speeding up the contract negotiation process among partners.

\section{ESTABLISHING TRUST RELATIONSHIPS}

In this section we address the establishment of trust relationships among organizations in VBEs. We first present some existing related approaches.

\subsection{Existing approaches for trust relationship establishment}

There are several approaches for establishing trust relationships which are applied for different actors in various kinds of environments. These approaches are applied to the establishment of trust relationships either among individuals, among actors in specific domain (e.g. in health service provision), or among entities in a specific technology (e.g. agent technologies). Although the following few cannot be directly applied for trust relationships among organizations, they do have relevance: rolebased, reputation-based, interaction-based, and risk-based approaches.

Role based approach: Role-based trust relationships are established to facilitate responsibilities related to roles of organizations in collaborative networks. This approach is mostly used for establishment of trust relationships among systems representing organizations and those systems are either using multi agent systems or peer-to-peer interactions on Internet based relationships [Huynh, D. et al 2004]. Each peer, node or agent represents a single organization in the dynamic community interacting through the Internet. The approach was developed as a solution to the trust relationship problems in the decentralized and dynamic working environments [Field, S. et al 2003]. With this approach, an organization cannot take more than one role and it is trusted only for a specific known role. This approach can be applied to create trust of the member organizations to the VBE administrator. Thus the VBE administrator is trusted to take the VBE related administrative tasks.

Reputation based approach: At individual level, reputation is an overall quality or character as seen or judged by people within a community. There are two possible sources for reputation information of an organization for establishing trust relationship with others. First is the Witness reputation that refers to the reputation information collected by the trustor or the trustor's associated (friends) organizations [Huynh, D. et al 2004]. In this case the trustor must observe the required character for the trustee or at least its associated organizations must observe. In VBEs, where 
organizations collaborate virtually, the adaptation of this approach is hardly feasible. And second is the Certified reputation that refers to the reputation information collected by the trustee and made available to the trustor. The trustee can provide its information such as the detailed organization's profile to the trustor to enhance its trust level [Yu, B. et al 2003]. The trustee can also request its friend/authorized organizations to provide positive information (e.g. accreditation document) to the trustor that can be used to enhance its trust level. The main problem for this approach is that there is high risk of using biased information and thus the resulted trust relationships are risked to failure. The validation of such information is also difficult since the bad reputation is usually hidden.

Interaction based approach: Past experiences obtained from direct interactions among organizations enhance the chance of successfully establishing their trust relationships. Yet, member organizations sometimes need to collaborate with others, which they had never collaborated with before, and even they do not know them physically. Thus this approach cannot apply in every case in VBEs.

Consumer-opinion based approach: This approach is applied to establish trust relationships among customers and suppliers/producers. It is based on expressed opinions, ranking or comments provided by customers on the quality of products/services they purchase/use. While buying/using products/services, the customers are typically requested by a website to comment (rank) the quality of the same product/service (e.g. a television or a hotel room, etc.) from a number of producers/providers. Then, the comments (ranks) are usually organized by that site in a scorecard format. The results from the scorecard are then made available to future customers, for smoothing the creation of trust to certain producers/providers. In most cases, this approach is applicable to online businesses and thus the proof of data validity might be difficult.

Risk based approach: This approach focuses on reducing possible risks that may exist during the collaboration. As such organizations can trust each other and thus collaborate because of the confidence that limited risks may be encountered. However, in practice risks are unexpected results and cannot be predicted to when they will arise. Thus it is hard to practically avoid risks. It is even difficult in VBEs where virtual collaboration and cooperation are the key approach for co-working.

\subsection{Establishing trust relationships among organizations in VBEs}

To properly establish trust relationships among organizations in VBEs, which will be fruitful, several steps must be followed. We suggest four main steps: assessment of trust level of organizations, validation of trust level results, presentation and interpretation of trust levels, and creation of trust among organizations.

\section{Step 1: Assessment of trust level of organizations}

The fundamental step during the establishment of trust relationships among organizations is assessing their trust level. This step aims at ensuring that the involved organizations do have acceptable trust levels and also their trust levels are rightly balanced. In VBEs the assessment of trust level of organizations is performed for three purposes namely for ensuring that: (1) the trust of a VBE membership applicant meet the minimum trust level acceptable in the VBE, namely the base trust level, (2) all member organizations conform to the base trust level specified in the $\mathrm{VBE}$, and (3) the specified trustworthiness for an objective is met by all involved partners. In our approach for the assessment of trust level, the measurements are not 
absolute rather comparative. The trust levels are valid for given: rating, involved organizations, and set of trust criteria preferred by the trustor. The assessment of trust level of organizations is addressed in detail in [Msanjila, S.S. et al 2007-1].

\section{Step 2: Validations of trust level results}

The assessment of trust level applies the values of trust criteria provided and made available in the VBE by the respective organizations. The source of information can be either the organization's businesses or participations in VOs. A priori to confirming the resulted trust levels of organizations the information applied for each organization must be validated. By validating the applied information the resulted trust levels will also be validated. In this paper we suggest some sources of evidences that can prove the validity of information made available in the VBE by each organization. The information validity evidence is addressed in section 7 .

\section{Step 3: Presentation and interpretation of trust levels}

Our approach for the assessment of trust level is based on set of trust criteria that are selected by either the VBE administrator or the trustor. Thus the resulted trust levels are also expressed in terms of these trust criteria. Understanding and properly interpreting trust levels described in terms of values for a set of trust criteria will be complex and difficult to most decision makers, such as managers, directors, etc. who are not trust experts. Therefore, trust levels must be presented in a format which is as understandable as possible. However, an assistance of trust experts, in specific domain or environment, to interpret the trust levels will be helpful to decision makers. In this study we have suggested a qualitative means for representing the comparative trust levels in five ratings namely: strongly less trustworthy, less trustworthy, average trustworthy, more trustworthy, and strongly more trustworthy. Figure 1 shows the relations among these qualitative trust levels.

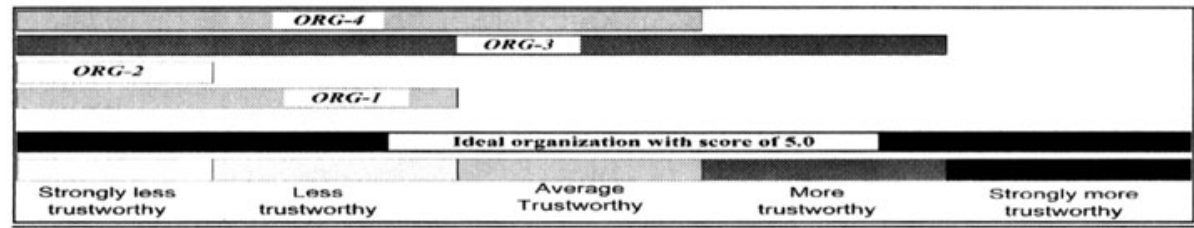

Figure 1: Trust-meter for representing trust levels among organizations

\section{Step 4: Creation of trust among organizations and initiation of their trust relationships}

When the valid trust level results are confirmed the organizations with acceptable trust level can be identified. To create trust among organizations each one must be convinced that others are trustworthy enough to establish trust relationships with them. Thus each organization needs enough information that will support understanding other organizations. However, the perceptions of trust and thus the preferred trust perspective are not uniform and can vary among the organizations. The challenge question is which information and at what level of details should be provided to each specific organization?

In our approach the creation of trust for the trustor organization to a trustee organization is based on the performance information of the trustee organization. Based on its preferred trust perspective the trustor organization shall be provided with detailed information enough to create the required trust. The detail of the information provided will also differ due to the following five aspects: 
- Who: The role of the actors during and after the establishment of their trust relationships

- When: The period when the information is gathered and provided

- What: The kind and the content of the information collected and provided

- How: The sources of information and the mechanisms for its collection and provision

- Why: The specific purpose for requesting the information and thus the trust objective.

When trust among the involved organizations is successfully created trust relationships among them can be initiated. Various forms for initiating established trust relationships are in practice, but the most popular one is the contracting. At this stage organizations trust each other and they thus guarantee each other, through the contract, that they can now start collaborating for the current common goals.

There are two kinds of trust relationships that can be established among organizations, namely: Short-term and Long-term trust relationships. Short-term trust relationships are established to facilitate co-working among organizations that will exist for a relatively short period of time, e.g. collaboration in VOs. Long-term trust relationships are established to facilitate co-working among organizations that will exist for a relatively long period of time, e.g. cooperation in VBEs.

\section{RISKS AND TRUST RELATIONSHIPS}

Risk refers to potential negative impact to an asset or value that may arise from present process or future event. Generally, risk is related to the potential losses, which can be caused by a risky transaction, and mainly addresses its probability.

\subsection{Risks that can occur during cooperation in VBEs}

Various types of risks exist in VBEs while member organizations are cooperating. These risks (Table 2) must be addressed and strategic response to reduce the severity of such risks must be put in place.

Table 2: Some risks that can occur during cooperation among organizations in VBEs

\begin{tabular}{|l|l|}
\hline Risk type & Description and sources \\
\hline Strategic risks & $\begin{array}{l}\text { Several different strategic risks may be associated with operating in different types of } \\
\text { business or industry domains. These include risks arising from: acquiring business } \\
\text { opportunity, changing customers, changes of customer's demands, changes of operating } \\
\text { environments, and emerged new innovative results from research and developments. } \\
\text { Organizational strategies must be flexible to accommodate the changes. Rigid strategies } \\
\text { can result risks such as failure of an organization to properly integrate and collaborate } \\
\text { with others due to unacceptable or outdated strategies [Anargiridou, D. C. 2006]. }\end{array}$ \\
\hline $\begin{array}{l}\text { Operational } \\
\text { risks }\end{array}$ & $\begin{array}{l}\text { Operational risks may exist due to direct or indirect loss resulted from inadequate or } \\
\text { failed internal processes, employees, or systems. Failure of an organization to achieve } \\
\text { agreed results due to its internal problems causes risk of failure to the entire consortium } \\
\text { configured for collaboration, and thus failure in achieving the common goals. }\end{array}$ \\
\hline $\begin{array}{l}\text { Legal } \\
\text { and } \\
\text { border risks } \\
\text { cross }\end{array}$ & $\begin{array}{l}\text { These are risks that may exist due to changes of government or local authorities, rules, } \\
\text { regulations and laws. Usually business organizations are not involved in proposing legal } \\
\text { issues and thus they have no influence. In the VBE however, organizations might belong } \\
\text { to different legal systems and even from different countries. Changes of legal issues in } \\
\text { one country where some members are located might cause risks for their cooperation } \\
\text { with others and vice versa for others. }\end{array}$ \\
\hline $\begin{array}{l}\text { Compliance risks are those associated with the need to comply with laws, regulations or } \\
\text { norms. They also apply to the need to act in a manner which other organizations and } \\
\text { customers expect, for example by avoiding opportunistic behavior. Since VBEs are not } \\
\text { closed border, various standards might exist in different markets. Collaboration among }\end{array}$ \\
\hline
\end{tabular}




\begin{tabular}{|l|l|}
\hline $\begin{array}{l}\text { Compliance } \\
\text { risks }\end{array}$ & $\begin{array}{l}\text { organizations operating in markets with different standards might face the risk of failure } \\
\text { to comply. In some cases these standards might even be contradicting. Compliance risks } \\
\text { are also associated with violation of, or non-conformance with, laws, regulations, norms, } \\
\text { and ethical standards. With, the current information and communication technologies } \\
\text { (ICTs) and the virtual co-working, assuring compliance becomes more difficult to prove. }\end{array}$ \\
\hline Financial risks & $\begin{array}{l}\text { These are the risks associated with financial aspects of the collaboration. They refer to } \\
\text { the chance that an actual investment's return is lower than expected. This includes the } \\
\text { possibility of losing some or all of the original investment due to issues such as customer } \\
\text { failure to pay, opportunism of partners in collaboration consortium, etc. Financial risks } \\
\text { are measured using the return for a specific investment. There are various kinds } \\
\text { of financial risks, among others they can be related to: credit, liquidity, transactions, } \\
\text { interest rate, foreign exchange, etc., risks }\end{array}$ \\
\hline $\begin{array}{l}\text { Reputation } \\
\text { risks }\end{array}$ & $\begin{array}{l}\text { Reputation risk is related to organization's image and instability arising from negative } \\
\text { opinions either from other member organizations in the VBE, or from the public. This } \\
\text { affects the organization's ability to establish new, or continue with the existing, trust } \\
\text { relationships with other organizations. This risk may expose the organization to litigation, } \\
\text { financial loss, or loosing its customers. Reputation risk exposure must be dealt with } \\
\text { throughout the organization, and requires exercising caution in dealing with its customers } \\
\text { and the community. }\end{array}$ \\
\hline $\begin{array}{l}\text { Risks surrounding ICTs, such as network failure, lack of resources and skills, hacking } \\
\text { and viruses, etc., have the potential of a greater negative impact on an organization than } \\
\text { in the past. Collaboration and cooperation are both facilitated by computer networks. } \\
\text { risks }\end{array}$ \\
$\begin{array}{l}\text { Several risks exist related to collaboration to which an organization must be prepared to } \\
\text { quickly respond. These include: security, privacy, information access, applied technologies } \\
\text { complexity related risks, etc. }\end{array}$ \\
\hline
\end{tabular}

\subsection{Risks avoidance vs. commitment to trust relationships}

In investment, it is generally the case that the greater the risk that a person takes, the higher the return that he/she will expect to receive, and the less risk entails lower return. The tradeoffs concerning organizations in relation to risks are about the values that will be received or obtained once a specific risk is accepted. However, the cooperation among organizations in VBEs does not provide a direct return value. The economical benefits of cooperation among member organizations are the increase in their chance of acquiring better and more opportunities, as well as involvement in opportunities brokered with others.

In practice, trust and risks are inversely related - when one increases there is a high chance of the other to decrease. Thus if risks existing in a certain environment increase then organizations operating in such environment feels at risky and can hardly trust each others for collaboration. Similarly, if organizations strongly trust each other then they feel that risks while collaborating can hardly arise.

Considering the style of co-working in VBEs - the virtual cooperation organizations may interact with others without knowing them physically and thus the feeling of possibility that such risks and even more can arise might be high. A number of risks exist in VBEs as discussed in section 6.1. One strategy that organizations can assume to avoid risks related to collaboration is either not committing themselves into trust relationships or resist establishing such trust relationships by being reluctant in creating trust to others. Such strategy can in fact cause problems related to sharing resources, knowledge, and competency as well as exchanging information necessary for enabling the collaboration.

In VBEs, cooperation is the only potential style of co-working that has so far been proved to be suitable for member organizations in such environments. Trust and trust relationships have illustrated to be the amenable facilitators which smooth the cooperation among organizations in VBEs as well as their collaboration in VOs. The challenging issue for the VBE administrator is to convince the organizations to establish and commit to the trust relationships despite the existing risks. 


\subsection{Promoting trust relationships among organizations}

There are several complexities that member organizations might face when cooperating in VBEs. In addition to the risks addressed in section 6.2 these complexities can also make it difficult to establish trust relationships among organizations. Among others, they include: social, economical, technological, and behavioral complexities. However, once an organization is confident that there are potential benefits related to its involvement in the VBE, there is a high chance of successfully establishing trust relationship with other organizations. Promoting high trust levels for organizations will ease the process of establishing trust relationships among them. In this work we suggest four approaches for promoting trust level of organizations which in turn promotes the participation in trust relationships:

- Committed participation in VOs: Every VO does have requirements such as resources, competencies, etc., that each partner must possess. When an organization manages to participate in many VOs it indicates that it has the capabilities and enough trust level for collaboration. The participations in VOs enable it to improve its performance records, e.g. by clearing their bad image, if any, which in turn enhances its trust level.

- Higher level of VBE membership: A VBE is managed through the agreed working and operating principles. Therefore, there are some requirements and rules that a VBE member must meet and comply with in order to receive the membership. Three membership levels are defined in the VBE [Afsarmanesh, H. et al 2005] namely: the fully active, the loosely associated, and the external level (very loose) memberships.

- VBE's market performance and branding (market credibility): Branding and marketing done by the member organization in external markets not only enhance its trust level but also the reputation of the VBE and hence high chance for brokering opportunities. The organization that performs better in the market, such as bringing many opportunities to the VBE, has a high chance of successfully establishing trust relationships with others.

Point accumulation and rewarding: With this approach, mechanisms and tools must be developed to assess achievements which in turn form the basis for either awarding points upon being productive or deducing points upon failures. The points are accumulated and later are used as a quick indicator for the trustworthiness of organizations.

\section{INFORMATION VALIDITY EVIDENCE}

The information that is made available by a member organization to the VBE for the assessment of its trust level must be supported with some validity evidences. This section addresses the evidence that can prove the validity of trust related data.

\subsection{Witness evidence}

These evidences constitute some form of documents generated by third parties that although provide some proof of accuracy for their respective information they cannot be considered as official and authorized proofs. The witnessed evidences can include information obtained from: (1) Public channels, (e.g. the magazines, newspapers) and (2) Private channels, (e.g. recommendations). 
Although these evidences are not as strong as the authorized evidence, in the lack of authorized evidences and depending on the source of evidence, they can provide some assurance to the validity of the provided information. Clearly, the weight of this validity increases if the channels used (the source of the news or the person providing the recommendation) are publicly recognized. For example, reputable news media put extra effort into finding the truth about the story they report, while their report can only focus on certain aspects of the story and does not guarantee to provide a comprehensive coverage. Similarly, a letter of recommendation from A about B only shows a part of B's qualifications, as they are known to party $\mathrm{A}$.

\subsection{Authorized certified evidence}

The validity of information in this category is based on well-defined and agreed standards that the information must comply, and the validation is usually performed by authorized organizations. Following are the five suggested sources:

Accreditation: Accreditation is defined as an independent act of granting recognition to an organization as a proof that the respective organization meets and maintains the specified standards. For example, for health sector, accreditation is an independent external review process that assesses the quality of health care services in order to encourage improving performance and assuring the public on the quality of the services provided by the organizations [Lichiello et al 2002]. Accreditation standards are traditionally set at what are considered minimum achievable and allowed levels. Accreditation is practiced for quality, cost, and business processes.

Financial rating: Financial rating (credit rate) is a published ranking, based on detailed financial analysis performed by a credit bureau focusing on the financial history of an organization, and specifically as its ability to meet payment obligations. Members must validate and get approval of their financial record from authorized organizations that are involved in analyzing: rating, credit score, indepth financials, solvency, profitability ratios, bankruptcy prediction, etc.

Patent: A patent is a set of exclusive rights granted by an authorized party to an organization for a fixed period of time in exchange for the regulated or public disclosure of a certain device, method, process or composition of matter (substance) (known as an invention) which is new, inventive, and industrially applicable. Patents granted for organizations could be evidence on the provided performance data.

License: License is an official or legal permission to do or own a specified thing. A license can be a document, plate, or tag that is issued as proof of official or legal permission such as a business license. In law discipline, a license is an actual permission to an act in a way that would be otherwise unlawful. Intellectual property rights such as a copyright or trademark provide a license as a proof of being allowed to use, reproduce, or create an instance of the licensed work. License can also be used as a proof for validity of the information provided by an organization.

Certificate and awards: A certificate is an official document affirming some fact. For example, a business registration certificate testifies to basic facts regarding the formulation and formal existence of an organization. In computing and especially computer security and cryptography, the word certificate generally refers to a digital identity certificate, also known as a public key certificate. An award is something given to a person or organization to recognize excellence in a certain field. Such proof can also be used as a means of validating the information provided by an organization. 


\section{CONCLUSION}

Creating and managing trust among organizations has illustrated of its potential for smoothing and facilitating their cooperation in VBEs as well as their collaboration within VOs. This paper has addressed the subject: "establishment of trust relationships among organizations". It also presents the antecedents and importance of trust relationships in collaboration. The validity evidences of the information needed for assessing the trust level of organizations, which constitutes the base for establishment of trust relationships, are presented. Also, the risks that exist during the operation stage of the VBE are addressed.

Acknowledgement: This work was supported in part by the ECOLEAD project funded by the European Commission. The authors thank for contributions from partners in the ECOLEAD consortium.

\section{REFERENCES}

1. Afsarmanesh H., Camarinha-Matos L., A framework for management of virtual organization breeding environments, in Collaborative Networks and their Breeding Environments, Springer, pg. 35-49, 2005.

2. Anargiridou, D. C. A critical examination of the main types of the e-finance risks in Greece and how the Greek web financial organizations could handle them. In Business, Law and Technology: Present and Emerging Trends, [Kierkegaard, S.M. -editor], Vol. 2, ISBN87-991385-1-4, 2006.

3. Clay, K., Strauss, R. Trust, risk and electronic commerce. The 19th century lessons for the 21 st century. In the proceedings of the 93rd annual conference on Taxation, national tax association and ecommerce, Mexico, 2000.

4. Gambetta, D. Trust: Making and Breaking Cooperative Relations. Basil Blackwell. 1988.

5. Field, S., Hoffner, Y. Web services and matchmaking. In international journal of networking and virtual organizations. Inderscience enterprises Ltd, Vol. 2, No. 1, pg. 16-32, 2003.

6. Huynh, D., Jennings, N. R., Shadbolt, N. R. Developing an integrated trust and reputation model for open maulit-agent system. In proceedings of 7 th workshop on Trust, Privacy, Deception and Fraud in Agent Societies, USA, 2004.

7. Lichiello, P. and Turnock B.J. "Guidebook for Performance measurement". Turning point Collaboration for a new century in public health. 2002.

8. Mayer, R. C. Davis, J. H., Schoorman, F. D. An integrated model of organizational trust. Academic of Management review. Vol. 20, No. 3, pg. 709-734, 1995.

9. Morgan, R. M., Hunt, A.D. The commitment-trust theory of relationship marketing. In the journal of marketing, Vol. 58, No. 3,pg. 20-38, 1994.

10. Msanjila, S. S., Afsarmanesh, H. Modeling Trust Relationships in Collaborative Networked Organizations. International Journal of Technology Transfer and Commercialisation, Inderscience. ISSN (Print): 1470-6075. To appear in 2007-1.

11. Msanjila, S. S., Afsarmanesh, H. Trust Analysis and Assessment in Virtual Organizations Breeding Environments. International Journal of Production Research, Taylor \& Francis. ISSN: 0020-7543, pg. 1-43, April, 2007-2.

12. Msanjila, S. S., Afsarmanesh, H. HICI: An approach for identifying trust elements - The case of technological perspective in VBEs. In proceeding of International conference on availability, reliability and security (ARES-2007), pg. 757-764, Vienna. April 2007-3.

13. Mukherjee, A. A model of trust in online relationship banking. Journal of bank marketing, Vol. 21. No. 1, 2003.

14. Grandison, T., Sloman, M. A survey of trust in Internet applications. In IEEE communications survey and tutorials. Fourth quarter, 2000. Grandison, T., Sloman, M. A survey of trust in Internet applications. In IEEE communications survey and tutorials. Fourth quarter, 2000.

15. Rousseau, D. M., Sitkin, S. B., Burt, R. S., Camerer, C. Not so different after all: A cross-discipline view of trust. Academic management review Vol. 23, pg. 393-404, 1998.

16. Rtanasingam, P. Trust in inter-organizational exchanges: a case study in business-to-business electronic commerce. In the journal of decision support system, pg. 525-544, 2005. 